\title{
Sudden Sensorineural Hearing Loss after Lapaoscopic Sleeve Gastrectomy Under General Anaesthesia: A Case Report
}

\author{
Gabriele De Sena*2, Alfredo Allariaa ${ }^{1,2}$, Giovanni Giordano ${ }^{1}$, Danilo Porpora ${ }^{1}$, Rosa D’Amico ${ }^{1}$, \\ Vincenza Capuozzo ${ }^{3}$, Francesca Romana Ciorra ${ }^{4}$, Flavia D’Apice ${ }^{2}$ and Vincenzo Napolitano ${ }^{1,2}$ \\ ${ }^{1}$ Department of Translational Medical Sciences, University of Campania Luigi Vanvitelli, Italy \\ ${ }^{2}$ Integrated Assistential Department of General and Special Surgery, University of Campania Luigi Vanvitelli, Italy \\ ${ }^{3}$ Department of Surgery, "Santa Maria della Pietà" Hospital, Italy \\ ${ }^{4}$ Emergency and Acceptance Department, AORN Cardarelli, Italy \\ *Corresponding author: Gabriele De Sena, UOSD Endoscopic Surgery, Integrated Assistential Department of General and Special \\ Surgery, University of Campania Luigi Vanvitelli, Italy
}

\section{ARTICLE INFO}

Received: May 16, 2020

Published: 幽 June 08, 2020

Citation: Gabriele De S, Alfredo A, Giovanni G, Danilo P, Rosa D, et al., Sudden Sensorineural Hearing Loss after Lapaoscopic Sleeve Gastrectomy Under General Anaesthesia: A Case Report. Biomed J Sci \& Tech Res 28(1)-2020. BJSTR. MS.ID.004608.

\section{ABSTRACT}

We discuss the presentation of a sudden sensorineural hearing loss (SNHL) occurred as a rare complication after laparoscopic sleeve gastrectomy (LSG). Etiology of this complication is not clear, it seems that diverse and complex pathogenetic mechanism are involved so the prevention and treatment seems to be difficult.

Abbreviations: SNHL: Sensorineural Hearing Loss; LSG: Laparoscopic Sleeve Gastrectomy; NMR: Nuclear Magnetic Resonance; CSF: Cerebrospinal Fluid; HBOT: Hyperbaric Oxygen Therapy

\section{Introduction}

We report a case of a sudden sensorineural hearing loss (SNHL) occurred as a complication after laparoscopic sleeve gastrectomy (LSG) under general anaesthesia. Today, sleeve gastrectomy (SG), is one of the predominantly performed bariatric surgical procedures and laparoscopic techniques is the Gold standard [1-3]. This bariatric operation creates a sleeve-shaped stomach along the lesser curvature determining good results in reduction of excess weight through a double mechanism: a reduction in stomach's volume and a reduction in the ghrelin's secretion, an oxidizing hormone produced mainly in the gastric fundus cells' level deleted with this surgical procedure [4].

\section{Case Report}

A 25-year-old woman suffering from morbid obesity undergoes LSG under general anaesthesia. The past clinical history was not significant except for smoking and latex allergy. She had never experienced surgery and anaesthesia. She had never suffered from ontological diseases; she usually did not take any medication and had never taken any ototoxic drugs. At the admission, the physical examination and laboratory tests showed no significant alterations (Table 1). Anaesthesia was conducted with the balanced anaesthesia technique which defines a combination of agents and techniques to obtain premedication, general anaesthesia, muscle relaxation and analgesia [5] (Table 2). 
Table 1: Clinical Characteristics.

\begin{tabular}{|c|c|}
\hline Parameters & Baseline \\
\hline Age (Years) & 25 \\
\hline Height $(\mathrm{cm})$ & 170 \\
\hline Body Weight (Kg) & 133 \\
\hline BMI $\left(\mathrm{Kg} / \mathrm{m}^{2}\right)$ & 46 \\
\hline Fever (0C) & 36 \\
\hline White blood cells $\left(\mathrm{x} 10^{3} / \mu \mathrm{L}\right)$ & 13,4 \\
\hline Neutrophil $\left(\mathrm{x} 10^{3} / \mu \mathrm{L}\right)$ & 9,02 \\
\hline Neutrophil (\%) & 67,4 \\
\hline Lymphocytes $\left(\mathrm{x} 10^{3} / \mu \mathrm{L}\right)$ & 2,89 \\
\hline Lymphocytes (\%) & 21,6 \\
\hline Monocytes $\left(\mathrm{x} 10^{3} / \mu \mathrm{L}\right)$ & 1,07 \\
\hline Monocytes (\%) & 8 \\
\hline Hemoglobin (g/dL) & 14,7 \\
\hline Hematocrit (\%) & 44,7 \\
\hline Platelets $\left(\mathrm{x} 10^{3} / \mu \mathrm{L}\right)$ & 383 \\
\hline Albumin (g/dL) & 4,1 \\
\hline Total Protein (g/dL) & 6,9 \\
\hline Iron $(\mathrm{mcg} / \mathrm{dL})$ & 137 \\
\hline Sodium (mmol/L) & 136 \\
\hline Potassium (mmol/L) & 4,4 \\
\hline Calcium (mg/dL) & 9,4 \\
\hline $\begin{array}{l}\text { Partial Thromboplastin Time [APTT] } \\
\text { (sec) }\end{array}$ & 29,7 \\
\hline Prothrombin Time [PT] Activity (\%) & 119,7 \\
\hline PT/International Normalized Ratio [INR] & 0,86 \\
\hline FT3 $(\mathrm{pg} / \mathrm{mL})$ & 4,03 \\
\hline FT4 (ng/dL) & 1,17 \\
\hline $\mathrm{TSH}(\mu \mathrm{L} \mathrm{U} / \mathrm{mL})$ & 2,78 \\
\hline Blood Group & B \\
\hline Rh Factor & Positive \\
\hline HBsAg & Negative \\
\hline HCVAb & Negative \\
\hline HBsAG Antigen Australia & Negative \\
\hline HCVAB & Negative \\
\hline Glycemia mg/dl) & 87 \\
\hline
\end{tabular}

Table 2: Anesthesia Drugs.

\begin{tabular}{|c|c|}
\hline Premedication & Midazolam, $\mathbf{1}$ - $\mathbf{~ m g}$ \\
\hline \multirow{3}{*}{$\begin{array}{c}\text { Induction of General } \\
\text { Anaesthesia }\end{array}$} & Propofol 1.5 - $2.5 \mathrm{mg} / \mathrm{kg}$ \\
\cline { 2 - 2 } & Fentanyl $1-1.5 \mathrm{gamma} / \mathrm{kg}$ \\
\cline { 2 - 2 } & Rocuronium $0,6 \mathrm{mg} / \mathrm{kg}$ \\
\hline $\begin{array}{c}\text { Maintenance of General } \\
\text { Anaesthesia }\end{array}$ & Desflurane $5-6 \% ; 1-3 \mathrm{gamma} / \mathrm{kg}$ \\
\cline { 2 - 2 } & Rocuronium $0,15 \mathrm{mg} / \mathrm{kg} / 40$ minutes \\
\hline
\end{tabular}

The sleeve gastrectomy was performed in laparoscopy [6]. In order to gain better access to the subdiaphragmatic region, the patient was placed, during surgery, in supine position in anti-Trendelenburg and with legs spread. As laparoscopic entry techniques we used a Verres-type needle (14g; $120 \mathrm{~mm}$ ) along the lateral margin of the left rectus abdominal muscle at the height of McBurney's point. We used a standard-pressure (12-14 $\mathrm{mmHg}$ ) $\mathrm{CO}_{2}$ pneumoperitoneum. Five trocars were placed for access to the peritoneal cavity (2: $5 \mathrm{~mm} ; 312 \mathrm{~mm})$. An ultrasonic system (Harmonic scalpel) was used for haemostasis and tissue dissection. Gastric transecting and suture were performed with a mechanical stapling device (Ethicon's Echelon Flex GST System). Resected stomach was extracted through a small laparotomy in the left side. The procedure lasted two hours and forty minutes; the surgical time was about two hours and ten minutes. There were no surgical complications and no excessive blood loss. During the procedure, there was no respiratory, cardiac, nephrological, etc. complications and the hemodynamic remained stable.

As analgesic purpose, intravenous injection was performed with ketorolac, tramadol, metoclopramide, ranitidine. Sixty minutes after the end of the procedure she accused an unpleasant hearing loss on the right ear and contextually the perception of the same ear with an annoying noise: a tinnitus, no vertigo. The patient was submitted to a visit by an otolaryngologist, biometric examination, brain and brainstem nuclear magnetic resonance (NMR), tympanogram and audiogram. Physical examination of the ear was negative: the tympanic membranes was intact and normal; brain and brainstem NMR were negative and so biometric examination; there was not suggestive elements of otitis neither bacterial nor viral. Tympanogram was negative (Figure 1); the audiogram showed normal results in the right ear, instead in the left ear a hearing loss occurred with tonal island at 125, 250, $500 \mathrm{MHz}$. The patient, according to the otorhinolaryngology's indications, was treated with parenteral prednisol $40 \mathrm{mg} /$ day for six days, then with oral prednisol $20 / \mathrm{mg} /$ day for other seven days. She was discarded after seven days. At the control audiometry performed after two months there was no improvement.

\section{Discussion}

SNHL is defined as a hearing loss of at last $30 \mathrm{~dB}$ found in three sequential frequencies in the standard pure-tone audiogram over three days [7]. The Aetiology is idiopathic in $90 \%$ of cases instead in $10 \%$ of patients' causes are heterogeneous, the common ones include accidents, cranioencephalic traumas, infections and metabolic diseases. SNHL is reported as perioperative complication. SNHL after surgical procedures in spinal anaesthesia or lumbar puncture has been reported frequently as well as complication after otologic surgery and cardiopulmonary bypass [8-10]. However, in literature there are only few cases occurred after non otologic and non-cardiopulmonary surgical procedures carried under general anaesthesia; among these, as we found, only three procedures have been associated to laparoscopic surgery conducted under general anaesthesia, no one after bariatric surgery [11-15]. The case described is the first one reported occurred in association with a bariatric procedure. SNHL for non-cardiopulmonary surgery in general anaesthesia seems to be rare (Figure 2). 


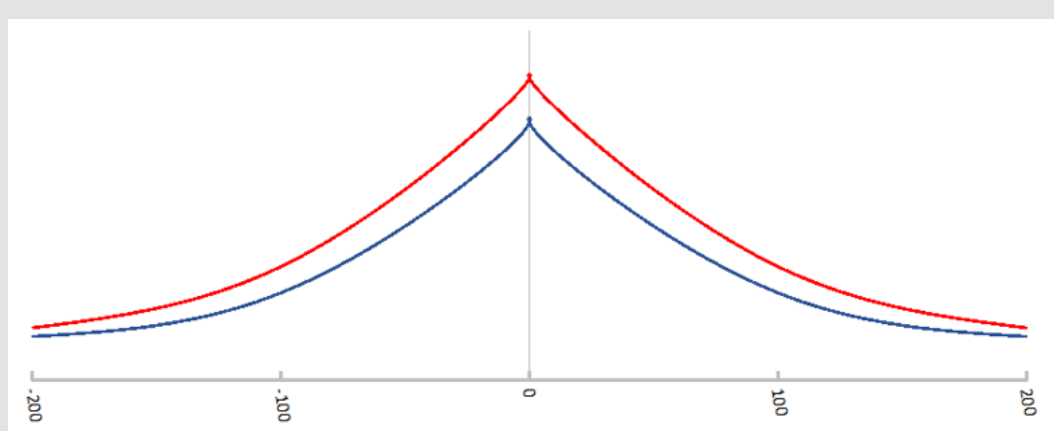

Figure 1: Tympanogram: on the right ear (blue line) and on the left one (red line) impedance testing was normal.

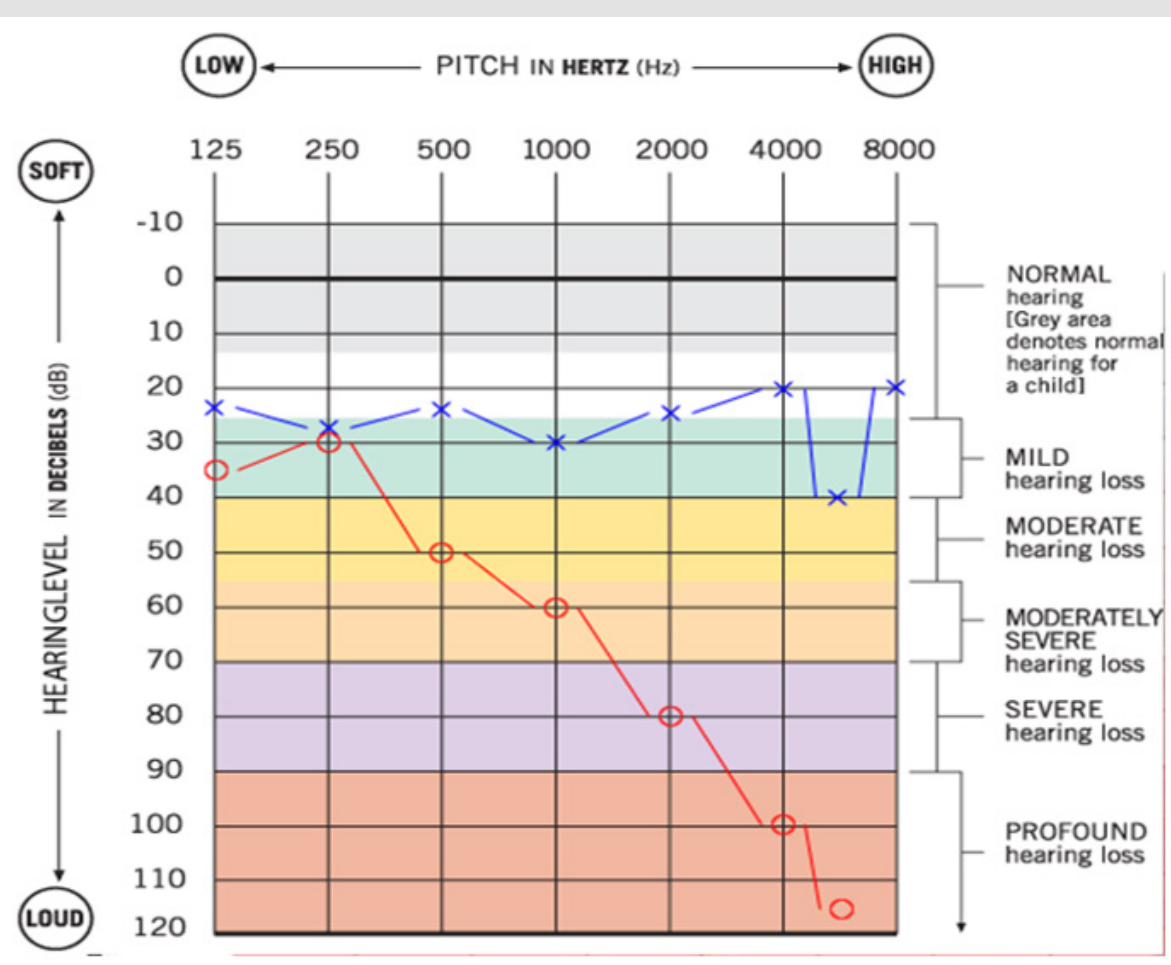

Figure 2: Audiogram at the onset of symptoms: on the left ear ( $X$ - blue line) is normal, on the right one $(0$ - red line) there is hearing loss with a tonal island (a region of the tonal continuum within which auditory sensitivity is normal) at $125,250,500$ $\mathrm{MHz}$.

A metanalysis of Warltier et al. reported 35 cases of SNHL after surgery under general anaesthesia, instead we found only three cases of SNHL after laparoscopy surgery: an appendicectomy, a cholecystectomy and a cystectomy. Generally, no patient has a preoperative hearing assessment [16]. Aetiology of hearing loss associated with non-otologic surgery and non-cardiopulmonary surgery carried in general anaesthesia is not clear, however there are some pathogenetic mechanism that seems to be involved: changes in middle ear pressure (mechanic and pharmacology), vascular pathology, Cerebrospinal Fluid (CSF) pressure changes, embolism, ototoxic drugs, and other miscellaneous causes. Obesity seems to have no role on the Aetiology and prognosis of SNHL [17]. Mechanic changes in middle ear pressure lead to damage of the tympanic membrane, of the round window, and of the conducting structures thus resulting in significant hearing loss [18-20]. This has been described as occurring during cardiopulmonary resuscitation. It appears that during mask ventilation, excessive pressure was transmitted to the Eustachian tube causing the middle ear damage. Pharmacologic chances in middle ear pressure are associated to the use of nitrogen dioxide $\left(\mathrm{N}_{2} \mathrm{O}\right)$ during anaesthesia. $\mathrm{N}_{2} \mathrm{O}$ is reported to be capable of causing variations of middle ear pressures that could lead to the tympanic perforation.

Decreased blood flow or thrombosis of the microcirculation during general anaesthesia either in the stria vascularis or the vessels of the spiral ligament, can result in ischemic damage of the hair cells and hearing loss. During laparoscopy surgery there is an increased intra-abdominal pressure due to carbon dioxide insufflation $\left(\mathrm{CO}_{2}\right)$ that reduces the venous return to the heart, furthermore during laparoscopic sleeve gastrectomy (LSG) the anti-Trendelenburg position of the patient during operation can 
increase this condition. That may change arterial pressure and/ or CSF pressure and that can be direct and indirectly conducted to ear structure causing its lesion [20-23]. According to Linares at al. Speculations [13], during laparoscopic surgery pneumoperitoneum with $\mathrm{CO}_{2}$ (more anti-Trendelenburg position) the increasing in intrabdominal pressure, reducing venous return and determining hypotension and tendencies to thrombosis, could lead to changes on cardiac, renal and hepatic function of the patient, causing metabolic alteration as hypercapnia and acidosis, and rarely air embolism and cardiac irritability (Figure 3).

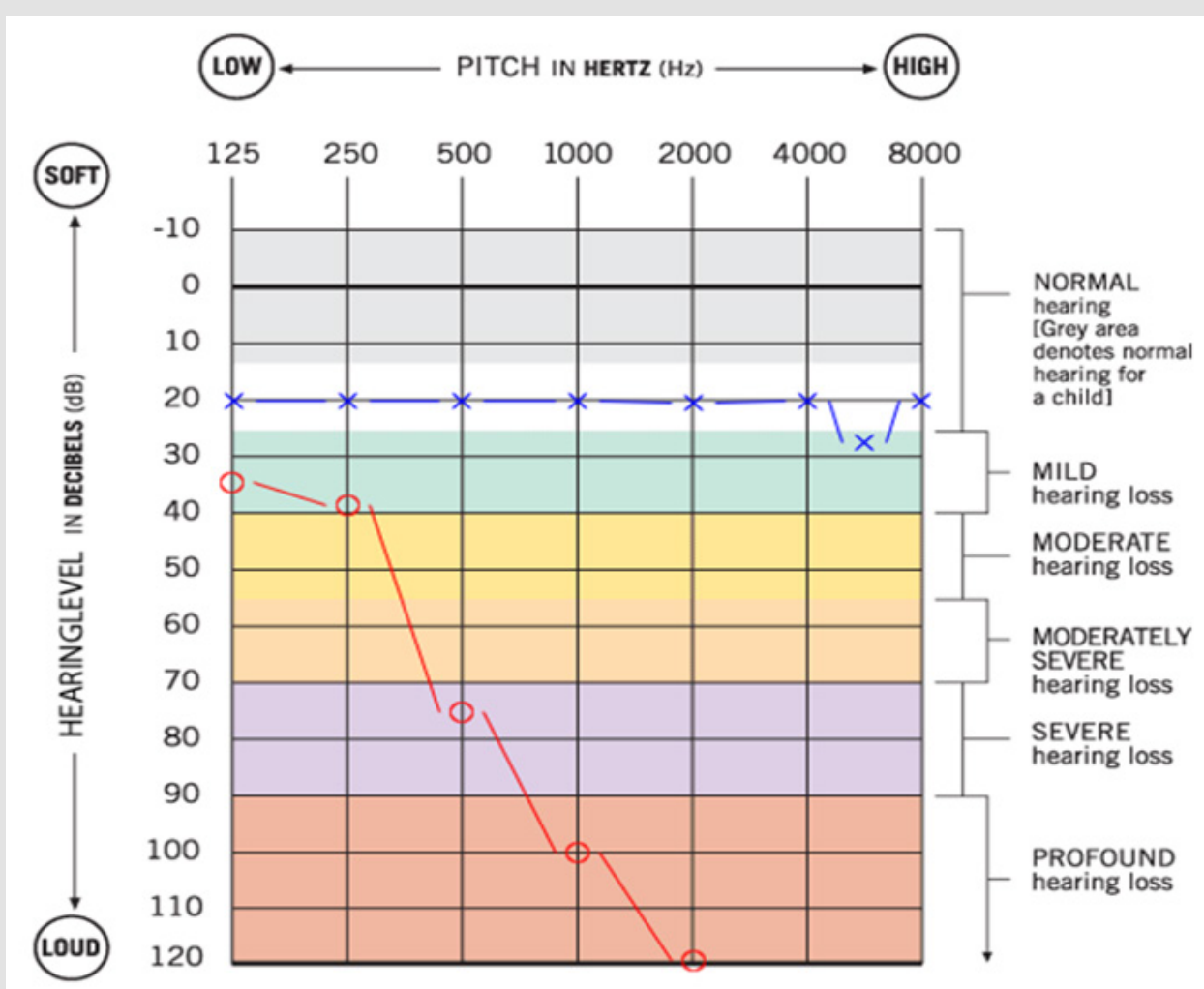

Figure 3: Audiogram after two months: on the left ear ( $X$ - blue line) is normal, on the right one $(0$ - red line $)$ persists hearing loss with a tonal island (a region of the tonal continuum within which auditory sensitivity is normal) at $125,250,500 \mathrm{MHz}$.

Those factors could be responsible of a blood redistribution with deviation of blood from internal ear, an anatomic structure highly susceptible to relative ischemia due to the absence of collateral circulation and to the high energy metabolism. Epithelial damage on internal ear microcirculation causes reduction of the potential of cochlear work [24-26]. Evaluating this mechanism, the idea of damages produced on internal ear microcirculation during general anaesthesia, lead to lack of oxygen of the ciliated cells and hearing loss. Some authors [15] disagree with this etiological hypothesis because the widespread of laparoscopy should be associated with a greater number of these cases but these authors do not consider the possibility of minor clinical presentations that are may be overlooked. Treatment of SNHL is based above all on use of high dosage steroids, vasodilators and antihistamine, they seem able to give the best results. Some authors suggest the use of Hyperbaric oxygen therapy (HBOT) that improving oxygen supply to the inner ear could lead to improving hearing, but there are no prospective trials that prove the real effectiveness of it [27-31].

\section{Conclusion}

We believe that SNHL through various etiopathological and physio pathological mechanisms, that need to be well investigated, can be considered a possible and misunderstood complication following laparoscopic treatment of obesity carried in general anaesthesia, even if extremely rare. Probably more prospective trials are needed as well as a systematic pre-operative and postoperative assessment of the patient's hearing abilities to make a correct and early diagnosis and to establish prevention strategies and effective therapies.

\section{References}

1. Bolen SD, Chang HY, Weiner JP, Richards TM, Shore AD, et al. (2012) Clinical outcomes after bariatric surgery: a five-year matched cohort analysis in seven US states. Obes Surg 22(5): 749-763.

2. Sherman V, Brethaer SA, Chand B, Schauer PR (2007) Laparoscopic sleeve gastrectomy. Minimally invasive bariatric surgery pp. 173-178.

3. Buwen JP, Kammerer MR, Beekley AC, Tichansky DS (2015) Laparoscopic sleeve gastrectomy: The rightful gold standard weight loss surgery procedure. Surg Obes Relat Dis 11(6): 1383-1385.

4. Khaitan L, Shea BJ (2020) Laparoscopic vertical sleeve gastrectomy, long and short-term impact on weight loss and associated co-morbidities. Transl Med 8 (Suppl 1): S5.

5. Gupta D (2012) Balanced anaesthesia-baseline anaesthesia. Ann Neurol 72(4): 629-630

6. Palermo M, Gagner M (2020) Why We Think Laparoscopic Sleeve Gastrectomy Is a Good Operation: Step-by-Step Technique. J Laparoendosc Adv Surg Tech A 30(6): 615-618. 
7. Byl FM (1984) Sudden hearing loss: eight years' experience and suggested prognostic table. Laryngoscope 94(5 Pt 1): 647-661.

8. Lee CM, Peachman FA (1986) Unilateral hearing loss after spinal anaesthesia treated with epidural blood patch. Anesth Analg 65(3): 312

9. Millen SJ, Toohill RJ, Lehman RH (1982) Sudden sensorineural hearing loss: Operative complication in non-otologic surgery. Laryngoscope 92(6 Pt 1): 613-617.

10. Naessens M, Kuhweide R, Ampe W, Depondt M, D’Hont G (1994) Hearing loss following lumbar puncture: Case report and literature study. Acta Otorhinolaryngol Belg 48(4): 351-3555.

11. Evan KE, Tavill MA, Goldberg AN, Silverstein H (1997) Sudden Sensorineural Hearing Loss After N General Anaesthesia for Nonotologic Surgery. Laryngoscope 107(6): 747-752.

12. Soylu E, Emir S, Yıldırım YS (2013) Permanent Bilateral Sudden Sensorineural Hearing Loss after Acute Abdominal Surgery under General Anesthesia. Int Adv Otol 9(2): 279-282.

13. Linares RAP (2005) Sudden Sensorineural Hearing Loss after Genera Anaesthesia to Laparoscopic Colecystectomy. International Archives of Otorhinolaryngology.

14. Belan A, Rida A, Hamoud N, Riou B, Vergel M (1994) Bilatera sensorineural hearing loss after general anaesthesia. Ann Fr Anesth Reanim 13(3): 400-402.

15. N Aydin, Aydin Y, Uludag S (2015) Sudden sensorineural hearing loss after laparoscopic cystectomy under general anaesthesia, J Obstet Gynaecol 35(2): 206-208.

16. Warltier D, Sprung J, Bourke D, Contreras MG, Warner ME (2003) Perioperative hearing impairment. Anesthesiology 98(1): 241- 257.

17. Hwang JH (2015) Role of Obesity on the Prognosis of Sudden Sensorineural Hearing Loss in Adults. Otolaryngol Head Neck Surg 153(2): 251-256

18. Goodhill V (1971) Sudden deafness and round window rupture. Laryngoscope 81(9): 1462-1474.

19. Goodhill V, Brockman SJ, Harris I, Hantz O (1973) Sudden deafness and labyrinthine window ruptures: Audio-vestibular observations. Ann Otol Rhinol Laryngol 82(1): 2-12.

ISSN: 2574-1241

DOI: 10.26717 /BJSTR.2020.28.004608

Gabriele De Sena. Biomed J Sci \& Tech Res

This work is licensed under Creative

Commons Attribution 4.0 License

Submission Link: https://biomedres.us/submit-manuscript.php
20. Friedman SI, Sassaki CT (1975) Hearing loss during resuscitation. Arch Otolaryngol 101(6): 385-386.

21. Perreault L, Normandin N, Plamondon L, Blain R, Rousseau P, et al. (1982) Middle ear pressure variations during nitrous oxide and oxygen anaesthesia. Can Anaesth Soc J 29(5): 428-434.

22. Waun JE, Sweitzer RS, Hamilton WK (1967) Effect of nitrous oxide on middle ear mechanics and hearing acuity. Anesthesiology 28: 846-850.

23. Segal S, Man A, Winerman I (1984) Labyrinthine membrane rupture caused by elevated intratympanic pressure during general anesthesia. Am J Otol 5(4): 308-310.

24. Man A, Segal S, Ezra S (1980) Ear injury caused by elevated intratympanic pressure during general anaesthesia. Acta Anaesthesiol Scand 24(3): 224-226.

25. Warltier D, Sprung J, Bourke D, Contreras M, Warner M, et al. (2003) Perioperative hearing impairment. Anesthesiology 98(1): 241-257.

26. Chao TK (2004) Sudden sensorineural hearing loss after rapid reduction of blood pressure in malignant hypertension. Ann Otol Rhinol Laryngol 113(1): 73-75.

27. Wilson WR, Laird N (1980) The efficacy of steroids in the treatment of idiopathic sudden hearing loss. Arch Otolaryngol 106(12): 772-776.

28. Fisch U (1983) Management of sudden deafness. Otolaryngol Head Neck Surg 91(1): 3-8.

29. Fletcher SJ (2000) Hemodynamic consequences of high- and lowpressure capnoperitoneum during laparoscopic cholecystectomy. Surg Endosc 14(6): 596-597.

30. Bennett MH, Kertesz T, Perleth M, Yeung P, Lehm JP (2012) Hyperbaric oxygen for idiopathic sudden sensorineural hearing loss and tinnitus . Cochrane Database of Systematic Reviews 10: CD004739.

31. Eisenman D, Arts HA (2000) Effectiveness of treatment for sudden sensorineural hearing loss. Archives of Otolaryngology - Head and Neck Surgery 126(9): 1161-1164.

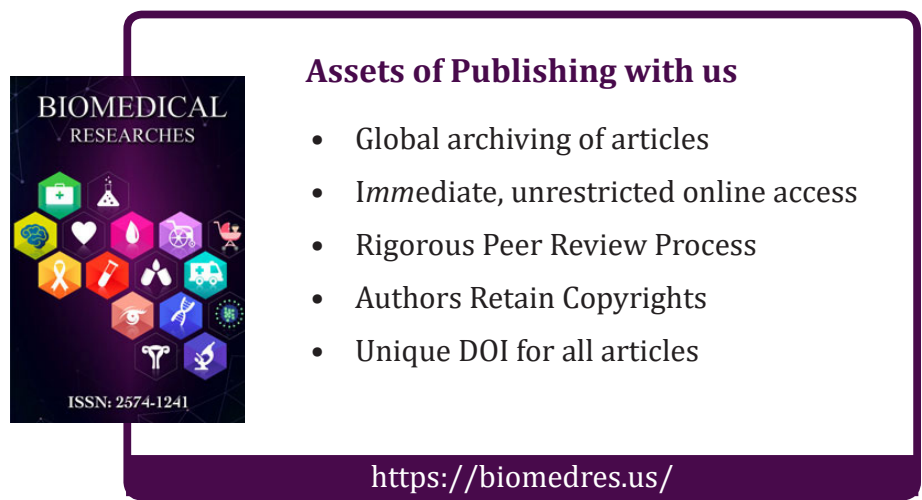

